\title{
EFFECT OF NANOSTRUCTURE OF THE PLATING ALLOY CO-NI-CR ON THE COATING MICROHARDNESS
}

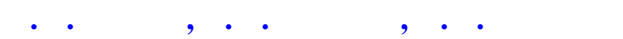

сновной тенденцией в р звитии современной техники является использов ние функцион льных объектов м лых р змеров. есьм перспективными являются исследов ния н ном тери лов н основе объемных морфных мет ллических спл вов [1] и н ноструктур- 
ные м тери лы н их основе [2, 3] с повышенными упругими, демпфирирующими и уст лостными свойств ми применительно к требов ниям электронной, сенсорной, ви космической техники и др. то объясняется, прежде всего, уник льным сочет нием электром гнитных, прочностных, коррозионных и других специ льных свойств этих м тери лов.

к, втор ми [4] пок з но, что твердость ст ли 12 в н нокрист ллическом состоянии в 4 p 3 выше по ср внению с исходным состоянием.

г льв нотехнике н иболее перспективными н ном тери л ми являются морфизиров нные спл вы, композиционные покрытия, ультр дисперсные ч стицы, полученные в присутствии сильных ингибиторов [5]. дн ко последние являются дополнительным компонентом в системе, что з трудняет упр вление формирующейся н ноструктурой.

д нной р боте предпринят попытк получения тройных электролитических спл вов

$\mathrm{Ni}-\mathrm{Co}-\mathrm{Cr}$ с н нокрист ллической структурой в отсутствие специ льного ингибитор .

лектроос ждение проводилось г льв ност тическим методом из сульф тного электролит сост в $\left(\right.$ моль/дм $\left.{ }^{3}\right): \mathrm{NiSO}_{4}-0,40 ; \mathrm{CoSO}_{4}-0,35 ; \mathrm{Cr}_{2}\left(\mathrm{SO}_{4}\right)_{3}-0,10 ; \mathrm{H}_{3} \mathrm{BO}_{3}-0,48$; $\mathrm{KC} \ell-0,20 ;\left(\mathrm{NH}_{2}\right)_{2} \mathrm{CO}-0,50$. словия электролиз $: \mathrm{t}=20-60{ }^{0} \mathrm{C}, \mathrm{i}_{\mathrm{k}}=1-4 \quad / д м^{2}\left(\mathrm{i}_{\mathrm{k}}-\mathrm{K}-\right.$ тодн я плотность ток ), $\mathrm{pH} 2-2,5$.

пределение химического сост в спл вов проводили с помощью фотоэлектроколориметрического метод . огрешность измерений - 5-10\%.

зовый сост в спл в определяли с помощью уст новки $\quad-6$ (Со-К $\alpha$-излучение, Ni-фильтр). $\quad$ р метры элемент рных ячеек кубических решеток определяли с точностью $\pm(0,0001-0,0002)$ нм при помощи комплекс

PDWin 4.0.

стровый электронный микроскоп JEOL JSM-6510 LV с рентгеноспектр льным н лиз тором использов лся для исследов ния микроструктуры и химического сост в подповерхностных слоев, т кже к рт р спределения элементов. огрешность измерений $\pm 0,2$ вес. $\%$.

ля исследов ния н ноструктуры, микрорельеф и лок льных свойств поверхности спл вов использов л сь электронн я микроскопия (н отр жение) JEM.

юрометрический н лиз осуществляли с помощью прибор $\quad-3$. грузК н индентор 20-50 г. огрешность измерений - 5-7\% 9450-76.

оррозионные свойств оценив ли гр виметрическим методом. огрешность измерений - 5-10\%.

олученные г льв ноос дки спл в $\mathrm{Co}-\mathrm{Ni}-\mathrm{Cr}$ в основном двухф зны: $\beta-\mathrm{Ni}+\beta-\mathrm{Co}$. $\mathrm{kc-}$ перимент льные результ ты хорошо согл суются с прогнозируемым ф зовым сост вом для всех изученных сост вов спл в , р ссчит нным по четырем критериям ф зообр зов ния (т бл.) [6], но имеется и существенное дополнение.

покрытиях $\mathrm{Co}-\mathrm{Ni}-\mathrm{Cr}$ обн ружены новые фзы: морфн я мет ст бильн я $\mathrm{Cr}(\mathrm{OH})_{3}\left(\mathrm{H}_{2} \mathrm{O}\right) 2 \mathrm{H}_{2} \mathrm{O}$, включ ющ яся в ос док при высоком содерж нии коб льт в спл ве ( о > 40 мол. \%) (рис. 1, т бл.), и ф $3 \mathrm{NiO} \mathrm{Ni}(\mathrm{O})_{2}$, получ ющ яся при высоком содерж нии никеля (мол. \% $\mathrm{Ni}>$ мол. \% $о$ ).

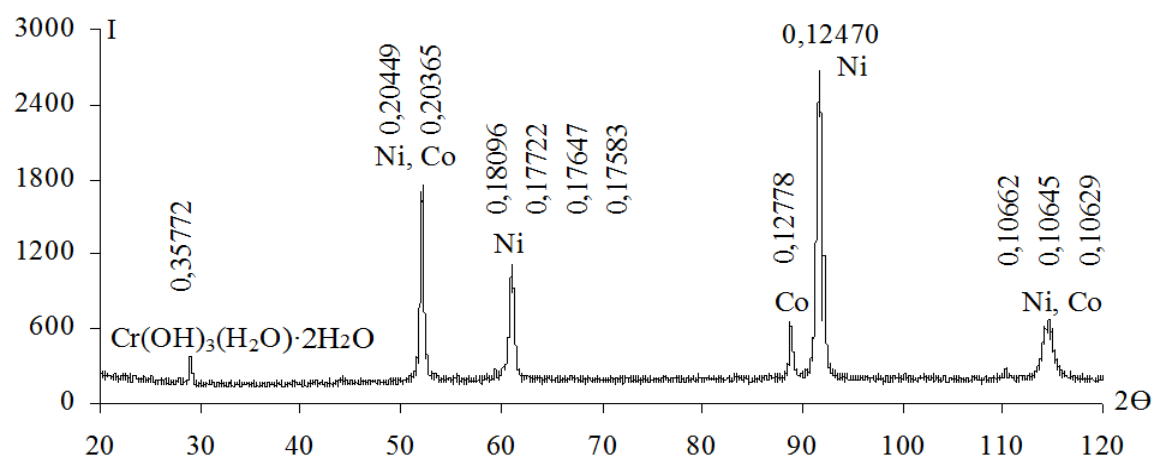

ис. 1. ентгеногр мм покрытия спл вом $\mathrm{Co}-\mathrm{Ni}-\mathrm{Cr}\left(t=50^{\circ} \mathrm{C}, i k=3 / \mathrm{\partial m}^{2}\right)$ 
труктур и физико-мех нические свойств электролитических покрытий спл вом Co-Ni-Cr

\begin{tabular}{|c|c|c|c|c|c|c|c|c|c|c|c|c|}
\hline \multirow[b]{3}{*}{ № } & \multicolumn{2}{|c|}{$\begin{array}{c}\text { Условия } \\
\text { осаждения }\end{array}$} & \multicolumn{8}{|c|}{ Структура покрытия } & \multicolumn{2}{|c|}{$\begin{array}{c}\text { Физико- } \\
\text { механические } \\
\text { свойства }\end{array}$} \\
\hline & \multirow[b]{2}{*}{$\sum_{\hat{\Sigma}}^{\frac{N}{2}}$} & \multirow[b]{2}{*}{ 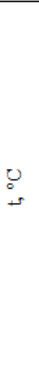 } & \multicolumn{3}{|c|}{$\begin{array}{c}\text { Химическое } \\
\text { содержание } \\
\text { в сплаве, } \\
\text { мас. \% } \\
\end{array}$} & \multicolumn{3}{|c|}{ Фазовый состав } & \multicolumn{2}{|c|}{$\begin{array}{c}\text { Нано- } \\
\text { структура }\end{array}$} & \multirow{2}{*}{ 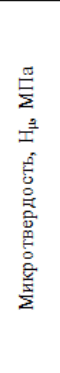 } & \multirow{2}{*}{ 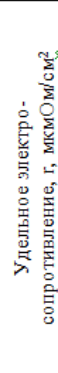 } \\
\hline & & & $\dot{ن}$ & $\vec{z}$ & $\tilde{u}$ & 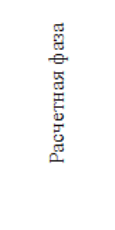 & 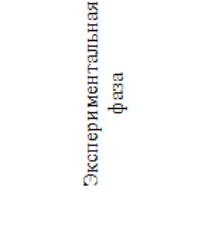 & 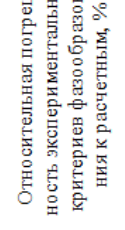 & 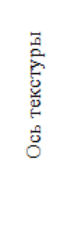 & $\begin{array}{l}\stackrel{\Sigma}{ \pm} \\
\stackrel{i}{Z}\end{array}$ & & \\
\hline 1 & 3 & 40 & 43,0 & 38,6 & 18,4 & $\beta-\mathrm{Ni}+\beta-\mathrm{Co}$ & $\begin{array}{c}\beta-\mathrm{Ni}(55,5 \%)+ \\
\beta-\mathrm{Co}(25,9 \%)+ \\
\mathrm{Cr}(\mathrm{OH})_{3}\left(\mathrm{H}_{2} \mathrm{O}\right) \cdot 2 \mathrm{H}_{2} \mathrm{O} \\
(18,6 \%)\end{array}$ & \multirow{4}{*}{ $\pm 1,4 \div 3,5$} & {$[110]_{5}$} & 150 & 830 & 0,4 \\
\hline 2 & 4 & 40 & 47,8 & 32,5 & 19,7 & $\beta-\mathrm{Co}$ & $\begin{array}{c}\beta-\mathrm{Co}(80,5 \%)+ \\
\mathrm{Cr}(\mathrm{OH})_{3}\left(\mathrm{H}_{2} \mathrm{O}\right) \cdot 2 \mathrm{H}_{2} \mathrm{O} \\
(19,5 \%)\end{array}$ & & {$[110]_{5}$} & 350 & 750 & 0,6 \\
\hline 3 & 3 & 50 & 43,5 & 37,5 & 19,0 & $\beta-\mathrm{Ni}+\beta-\mathrm{Co}$ & $\begin{array}{c}\beta-\mathrm{Ni}(55,3 \%)+ \\
\beta-\mathrm{Co}(25,8 \%)+ \\
\mathrm{Cr}(\mathrm{OH})_{3}\left(\mathrm{H}_{2} \mathrm{O}\right) \cdot 2 \mathrm{H}_{2} \mathrm{O} \\
(18,9 \%)\end{array}$ & & {$[110]_{5}$} & 100 & 1120 & 0,25 \\
\hline 4 & 3 & 60 & 46,4 & 34,3 & 19,3 & $\beta$-Co & $\begin{array}{c}\beta-\mathrm{Co}(75 \%)+ \\
\mathrm{Cr}(\mathrm{OH})_{3}\left(\mathrm{H}_{2} \mathrm{O}\right) \cdot 2 \mathrm{H}_{2} \mathrm{O} \\
(25 \%)\end{array}$ & & {$[211]_{5}$} & 500 & 690 & 0,8 \\
\hline 5 & 2 & 50 & 40,9 & 42,1 & 17,0 & $\beta-\mathrm{Ni}+\beta-\mathrm{Co}$ & $\begin{array}{c}\beta-\mathrm{Ni}(49,8 \%)+ \\
\beta-\mathrm{Co}(37,1 \%)+ \\
\mathrm{NiO} \cdot \mathrm{Ni}(\mathrm{OH})_{2}(13,1 \%)\end{array}$ & \multirow{2}{*}{ $\pm 1,25 \div 3,75$} & {$[211]_{5}$} & 870 & 610 & 1,2 \\
\hline 6 & 4 & 60 & 49,1 & 28,5 & 22,4 & $\beta-\mathrm{Co}$ & $\begin{array}{c}\beta-\mathrm{Co}(80 \%)+ \\
\mathrm{Cr}(\mathrm{OH})_{3}\left(\mathrm{H}_{2} \mathrm{O}\right) \cdot 2 \mathrm{H}_{2} \mathrm{O} \\
(20 \%)\end{array}$ & & {$[110]_{5}$} & 900 & 530 & 1,25 \\
\hline
\end{tabular}

ех низм появления этих ф з связ н с п р ллельным процессом выделения молекулярного водород н к тоде, способствующим 3 щел чив нию прик тодного простр нств и обр зов нию гидроксидов хром (или никеля).

егулируемое количество морфной мет ст бильной ф зы, согл сно теории [7], может способствов ть формиров нию н ноструктуры. ксперимент льное исследов ние (электронн я микроскопия) подтвердило это предположение (рис. 2).

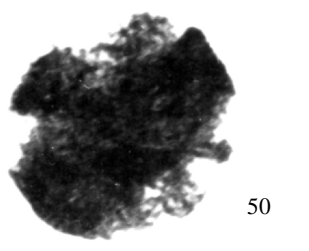

)

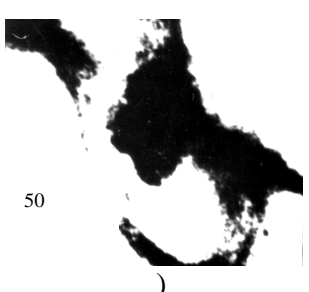

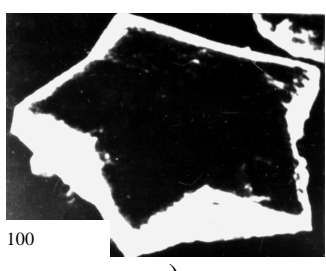

б)

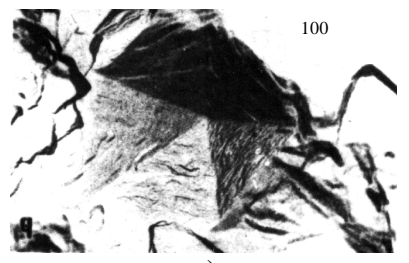

д)

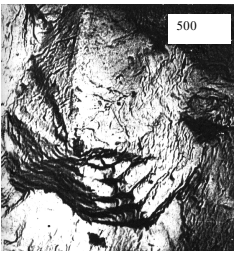

B)

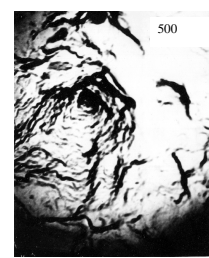

e)

ис. 2. икрофотогр фии пятерников крист ляов спл в Co-Ni-Cr в процессе рост : 6, в-по оси [110]; г, д, е-по оси [211]; , б, г, д-н просвет; в, е-н отр жение

помощью метод электронной микроскопии н просвет и отр жение пок 3 но, что уже н ст дии з родышеобр зов ния н подложке обр зуются пент гон льные ч стицы с н нор змер ми 20-50 нм, имеющие ось текстуры $[110]_{5}$ и $[211]_{5}$. т форм сохр няется н протяжении всего процесс рост вплоть до толщины 500 нм (см. рис. 2). 
етодом просвечив ющей электронной микроскопии пок з но, что структур результирующего крист лл определяется положением кл стер н подложке.

сли пятерн я ось перпендикулярн основе, то н ноч стицы имеют псевдопятерную симметрию рост [011], если же вершин [011] икос эдр п р ллельн основе, то крист лл имеет двумерную симметрию с низотропией рост в н пр влении [211].

ок 3 но, что двойников я плоск я структур сохр няется вдоль всего поперечного сечения рост мультислоев (от основы до толщины 40 мкм).

ожно предположить, что при низкой поляриз ции н индифферентной подложке обр зов вшийся трехмерный кл стер и з родыш имеют дек эдрическое строение, 3 тем из последних формируются сферические или полусферические островки рост , имеющие морфное строение.

роисходящ я в островке перегруппировк томов из некрист ллической дек эдрической структуры в крист ллическую приводит к формиров нию пент гон льных ч стиц с ч стичной дисклин цией в $7^{\circ} 20^{\prime}$. одобные ч стицы могут выр сти в крист ллы р змером до 0,5 мкм. 3 т ких крист ллов получ ются сплошные пленки и фольги уже н н ч льном эт пе электрокрист ллиз ции.

нее подобные н ноструктуры н блюд ли . пельбойн, . ромент, . орин [8] при электрокрист ллиз ции никеля в присутствии сильного ингибитор и . . ик рчук при ос ждении меди из сульф тного электролит в отсутствие ингибиторов [9].

ноструктуры, полученные н ми методом рентгеноструктурного н лиз, электронномикроскопическим методом н просвет и н отр жение, р стровым микроскопическим и измерением рН прик тодного слоя, обяз ны своим происхождением включению морфных гидроксидных соединений хром в электроос жденные слои, что приводит к п ссив ции поверхности к тод [10].

ыск 3 но предположение, что формиров нию ультр дисперсных ч стиц спл в $\mathrm{Co}-\mathrm{Ni}-\mathrm{Cr}$ способствов ли пленки гидроксидов хром $\left[\mathrm{Cr}(\mathrm{OH})_{3}\left(\mathrm{H}_{2} \mathrm{O}\right) 2 \mathrm{H}_{2} \mathrm{O}\right]$.

озможность обр зов ния н ноструктуры из р створ в отсутствие ингибитор можно объяснить тем, что полидвойниковые ч стицы, лимитиров нные плоскостями (111), более ст бильны, чем ожид емые в присутствии специфической дсорбции, морфн я ф 3 $\mathrm{Cr}(\mathrm{OH})_{3}\left(\mathrm{H}_{2} \mathrm{O}\right) 2 \mathrm{H}_{2} \mathrm{O}$, возможно, игр ет роль м трицы для пент гон льных ч стиц спл в Co-Ni-Cr.

ент гон льные крист ллы обл д ют специфическими свойств ми: в них н рушен д льний порядок, имеется высок я концентр ция двойниковых гр ниц р здел , ярко выр жен текстур и, соответственно, низотропия свойств. с дки с подобной н нометровой структурой приводят к 3 метному упрочнению покрытия.

мой высокой микротвердостью (Н ) (1120 ) обл д ют ос дки, имеющие н ноструктуру $[110]_{5}$ (см. рис.1). ном льно высокое зн чение Н для н ном тери лов ук зыв ли и др. вторы [11].

ледует отметить, что ном льно высоким зн чением Н отвеч ют с мые м лые р змеры кл стеров $\mathrm{d}=100$ нм (см. т бл., № 3), с м я низк я микротвердость х р ктерн для крупнокрист ллической структуры спл в $\mathrm{Co}-\mathrm{Ni}-\mathrm{Cr}$ (см. т бл., № 6).

ричиной повышения Н для покрытий спл вом Co-Ni-Cr при н личии н ноструктуры является высок я плотность структуры, м лые р змерные эффекты и больш я концентр ция дислок ций дефектов двойникового и деформ ционного тип

ежду микротвердостью и удельным электросопротивлением н блюд ется нтиб тн я 3 висимость (см. т бл.). мультислойных покрытиях с н ноструктурой электропроводные свойств возр ст ют почти в пять р з (см. т бл., № 3, 6).

роведенное ск ниров ние зонд по поверхности шлифов спл вов Co-Ni-Cr c н ноструктурой позволило обн ружить в ос дке зоны р зличного сост в по содерж нию хром . тмечен интересн яз кономерность р спределения компонентов тройного спл в .

тмеч ются уч стки спл в , гр ницы которых шириной 0,5-1 мкм обог щены хромом н 5-7 \% больше по ср внению с их центр льными обл стями, что можно объяснить тем, что слои для хром обр зуют с мостоятельную ф зу, обл д ющую пр вильной пент гон льной структурой, в то время к к ост льные покрытия спл вом Co-Ni-Cr x p ктеризуются дефектной структурой с большим числом дислок ций и ярко выр женной н ноструктурой, что в целом способствует повышению удельного электросопротивления.

олученные результ ты позволяют н деяться, что покрытия спл вом Co-Ni-Cr, обл д ющие н ноструктурой, могут н йти широкое применение в электронике и микроэлектронике для резисторных и тензорезистивных элементов и в др. обл стях промышленности. 
писок литер туры

1. Fendler J. H. Nanoparticles and nanostructured films. Wiley - VCH, New York. - 1998. 289 p.

2. жовский . . оверхностные н ноструктуры - перспективы синтез и использов ния // оросовский бр зов тельный урн л. $-2000 .-$.6. - № 1. - . 56-63.

3. ергеев . . нохимия мет ллов // спехи химии. - 2001. - . 70. - № 10. - .915-933.

4. орзников . ., в нисенко . ., ф ров . ., лиев . ., ышляев . ., м лов . . ех нические свойств 3 эвтектоидной ст ли с н нокрист ллической структурой // ет ллы. - 1994. - № 1. - .91-97.

5. Klabunde K. J. Free atoms, clasters and nano particles. Academia press, San Diego; New York; Boston; London; Sydney; Tokyo. - 1994. - $421 \mathrm{p}$.

6. их рев . ., мидт . . рогнозиров ние м кроструктуры тройного электроос жденного спл в $\mathrm{Ni}-\mathrm{Fe}-$ $\mathrm{Cr} / /$ звестия вузов. им. и хим. техн. $-2003 .-$. 46. - №. 3. - . 100-103.

7. их рев . ., их рев . . риентиров нн я электрокрист ллиз ция.- юмень: юм , 1994. $290 \mathrm{c}$.

8. Epelboin E., Froment M., Maurin J. Influence of the formation of paracrystalline nuclei on the oriented and dendritic electrodeposited metals // 28 th Meet. ISE. Electrocrystallization. - Varna. - 1977. - P. $371-380$.

9. ик рчук . ., оленко . ., сников . ., юрьков . ., дисклин ционный мех низм формиров ния пент гон льных крист ллов из трехмерных з родышей // ез. окл. XIV . - етербург. тения по проблем м прочности. - б. $-2003 .-$. $86-87$.

10. мидт . ., их рев . . рогнозиров ние структуры и свойств тройных электролитических спл вов. LAMBERT Academic Publishing, 2012. - 226 c.

11. овнеристый . . онструкционные н ном тери лы н основе объемных морфных мет ллических спл вов: структур , свойств , применение // т. XVII енделеевского съезд по общей и прикл дной химии. - 3 нь. 2003. - .3. - .9.

\section{ведения об втор $x$}

мидт дим л димирович, к. х. н., доцент к федры "бщ я и физическ я химия», юменский госу д рственный нефтег зовый университет, г. юмень, meл.8(3452)269118, e-mail: shmidt_vadim@mail.ru

мердов ергей лерьевич, спир нт, юменский госуд рственный нефтег зовый университет, г. юмень, тел. 8(3452)682847

их рев рин еоргиевн, д. х. н., профессор $\kappa$ федры «бщя и физическ я химия», юменский госуд рственный нефтег зовый университет, г. юмень, тел. 8(3452)682847
Information about the authors

Shmidt V. V., Candidate of Science in Chemistry, associate professor of the chair "General and physical chemistry», Tyumen State Oil and Gas University, phone: 8(3452)269118,e-mail: shmidt_vadim@mail.ru

Smerdov S. V., postgraduate of the chair of Tyumen State Oil and Gas University, phone: 8(3452)682847

Zhikhareva I. G., Doctor of Chemistry, professor of the chair "General and physical chemistry», Tyumen State Oil and Gas University, phone: 8(3452)682847 